\title{
Measuring personality in wave I of the national longitudinal study of adolescent health
}

\author{
J. Kenneth Young ${ }^{1}$, and A. Alexander Beaujean ${ }^{2}$ \\ Center for Doctoral Studies in Educational Leadership, Lamar University, Beaumont, TX, USA \\ 2 Department of Educational Psychology, Baylor University, Waco, TX, USA
}

Edited by:

Boaz Shulruf, University of Auckland, New Zealand

\section{Reviewed by:}

Jennifer Koran, Southern Illinois University, USA

Andrew Jones, American Board of

Surgery, USA

\section{*Correspondence.}

J. Kenneth Young, Center for Doctoral

Studies in Educational Leadership,

Lamar University, Beaumont 77710,

TX, USA.

e-mail:ken.young@lamar.edu
The researchers sought to develop a personality measure from items in Wave I of the National Longitudinal Study of Adolescent Health. The study found 13 items from three dimensions of personality (neuroticism, extroversion, and conscientiousness), and then examined the factor structure and internal consistency of each of the three dimensions. Within each personality dimension, the items showed a unidimensional factor structure and internal consistency estimates of the summed similar to scores from NEO Personality Inventories. The results can be used to further examine how child/adolescent personality is related to multiple mental and physical health outcomes in the Add Health database.

Keywords: personality, measurement, adolescent health, cognitive epidemiology

\section{INTRODUCTION}

Personality is a meaningful predictor of important life outcomes such as occupation selection (Filer, 1986), job performance (Ones et al., 1993; Judge et al., 1999), and academic success (Poropat, 2009). Moreover, personality factors have been found to be related to various health outcomes (Deary et al., 2010), such as mortality (Schwartz et al., 1995), accident involvement (Clarke and Robertson, 2005; Sümer et al., 2005), health behaviors and outcomes (Hampson et al., 2006; Roberts et al., 2007), and even health knowledge (Beier and Ackerman, 2003). Some even contend that most psychology-related variables used in studying health (e.g., optimism, hopelessness, self-efficacy, locus of control) simply reflect different aspects of personality (Marshall et al., 1994).

There are multiple conceptions of personality structure and the best way to measure the varying arrangements (Stankov et al., 1995), but many in the field have reached a working consensus that there are five broad, super-ordinate factors/domains from which a wide variety of personality-related behaviors and constellations can be classified (Digman, 1990; McCrae and Costa, 2008), commonly referred to as the Five Factor Model (FFM) or the "Big Five" (Digman, 1990; McCrae and Costa, 1997, 2008). The five factors are: Openness to Experience $(\mathrm{O})$, Conscientiousness (C), Extraversion (E), Agreeableness (A), and Neuroticism ( $\mathrm{N}$; see Table 1 for descriptions). Variability in these five factors appears to be strongly influenced by genetic factors (Loehlin, 1992), which may explain the emergence of these same personality factors across multiple cultures (McCrae and Costa, 1997; McCrae and Allik, 2002), as well as the stability in structure from childhood and adolescence to adulthood (Costa and McCrae, 1994; Caspi and Roberts, 2001), and throughout adulthood (McCrae and Costa, 2003).

\section{FIVE FACTOR MODEL AND HEALTH OUTCOMES}

Although the interface of personality and health outcomes is an under-researched area (Booth-Kewley and Vickers, 1994), the information currently available is relatively consistent in showing an adverse relationship between high $\mathrm{N}$ and mental and physical well being (Goodwin and Friedman, 2006), whereas high $\mathrm{C}$ tends to be related to more positive mental and physical health outcomes (Smith, 2006); moreover, these relationships tend to be relatively stable across the lifespan (Goodwin and Friedman, 2006; Martin et al., 2007; Kern and Friedman, 2008). E has shown a more equivocal relationship to health outcomes, showing both positive and negative health implications, while much less attention has been paid to how $\mathrm{O}$ and $\mathrm{A}$ have relate to mental (Kern and Friedman, 2008) or physical health (BoothKewley and Vickers, 1994).

The reason for the personality-health relationship is still not well understood, but there is some indication that there are at least three different, although not mutually exclusive, possible mechanisms for the relationship (Caspi and Roberts, 2001). First, personality differences may just be behavioral manifestations of differences in underlying pathogenesis. Second, since personality differences are associated with health-promoting or healthdamaging behaviors, the personality-health relationship might be attributed to the fact that people with certain personality constellations tend to engage in better/worse health-promotion. Third, personality differences may be more of a reflection of how people react to mental and/or physical illness, such as coping behaviors, modulation of distress, and treatment adherence. A major caveat in these studies, however, is that historically they have been confined to samples of adults. Thus Caspi et al. (2005) write that researchers in this area need to "turn their attention to earlier periods in development in order to understand enduring research and public health puzzles" (p. 475).

\section{CURRENT STUDY}

Given the potential importance of personality in understanding differences in health outcomes, it appears imperative that studies of child and adolescent physical and mental health include such measures. To that end, this study investigated the measurement of per- 
Table 1 | Description of the five-factor model of personality.

\begin{tabular}{|c|c|}
\hline Dimension & Description \\
\hline Neuroticism (N) & Characteristics are related to anxiety and emotional liability versus being placid and emotionally stable \\
\hline Extraversion (E) & $\begin{array}{l}\text { Characteristics are associated with enthusiasm toward life's circumstances, outgoing, and surgency versus introversion } \\
\text { gravity; encounter with oneself and one's life circumstances }\end{array}$ \\
\hline Openness to experience (O) & $\begin{array}{l}\text { Characteristics are associated with the willingness to have new experiences, engage new ideas, and be open to one's own } \\
\text { feelings versus being cynical and tough-minded }\end{array}$ \\
\hline Agreeableness (A) & $\begin{array}{l}\text { Characteristics are related to an inclination toward submission to others, passivity, and subduedness versus being } \\
\text { independent and having a strong will }\end{array}$ \\
\hline Conscientiousness (C) & Characteristics are related to being reliable, responsible, and having self-control versus impulsivity and casualness \\
\hline
\end{tabular}

Descriptions developed from Digman (1990).

sonality in Wave I of the National Longitudinal Study of Adolescent Health (Add Health; (Udry and Bearman, 1998). The Add Health study is a comprehensive examination of child/adolescent health, designed to measure numerous variables related to physical and mental well being in adolescence. Originally designed to investigate how social contexts (e.g., family, friends, schools, neighborhoods) and individual characteristics influence adolescent health and risk behaviors, the Add Health data includes variables related to physical and mental health; interpersonal relationships and sexual behaviors; education; delinquency and violence; adolescent involvement in adult roles; various genetic and biological measures of disease presence and processes; as well as a variety of measures about the environments in which the participants live, go to school, and work. Wave I of the study began collecting data during the 1994-1995 school year, when the participants were in grades 7-12, and the most recent wave of data (Wave IV) was collected in 2008 when the participants were between the ages of 24-32 years old. The most recent phases of the study examined the effects of the various contexts and health during the transition from adolescence to early adulthood.

There were no specific personality instruments used as part of the variables collected during the first three waves of data collection. However, a portion of the questions from Wave I of the study's questionnaires could possibly be used to develop a personality measure. To date, no study has examined these questions to determine: (a) if the survey questions from Wave I had a lexical relationship to questions from other measures specifically designed to measure personality? (b) If so, could any of the questions be aggregated to form a scale? (c) If questions could be aggregated, what is the internal consistency of such scales? and (d) Do these scales actually measure personality factors? Thus, this study was designed to answer these four questions with the hopes that if dimensions of personality can be measured in the Add Health data, they can then be used to investigate the relationship between child/adolescent personality traits and health outcomes both proximally (in childhood/adolescence) and distally (early adulthood).

\section{MATERIALS AND METHODS STUDY DESIGN}

The National Longitudinal Study of Adolescent Health (Add Health) was initiated in 1994 under a grant from the National Institute of Child Health and Human Development with co-funding from 17 other federal agencies. Researchers in this study collected data in multiple waves through the use of in-home, in-school, and school administrator questionnaires. It was designed to be the largest, most comprehensive survey of adolescents ever undertaken to study the health-related behaviors of adolescents (grades 7 through 12) and their outcomes in adulthood. Moreover, the Add Health sample has multiple sub-samples such as participants who are twins, adoptees, and siblings, as well as information on the participants' family and social networks, all of which can be used to help understand genetic and environmental influences on physical and mental health practices and outcomes (Duncan et al., 2001).

\section{Sample}

The sample for this study came from all the Add Health participants who completed the Wave I In-Home and In-School questionnaires $(n=20,745)$. Fifty percent of the respondents were female and their ages ranged from 11.42 years) to 21.42 years (mean 16.16 years, $\mathrm{SD}=1.72$ years). Of the 20,745 respondents, $12,747(61.45 \%)$ selfreported being Caucasian, 4,807 (23.17\%) were African-American, 1,584 (7.64\%) were Asian-American, 740 (3.57\%) were American Indian, with the remaining participants not identifying their race. In addition, 3525 (16.99\%) of the respondents self-reported having Hispanic ethnicity.

\section{Instrument development and psychometric analysis}

To develop measures of personality traits from the Add Health Wave I survey items, we combined the lexical (John et al., 1988) and factor analytic (Floyd and Widaman, 1995) approaches. Both methods have a long history in the development of personality scales (Eysenck and Eysenck, 1985; Barenbaum and Winter, 2008) and both approaches have made contributions to the measurement and understanding personality (Lohman and Rocklin, 1995).

Lexical approach. First, we selected a criterion instrument that was designed to measure the FFM personality domains and subsequently made a list of the all the item stems in each of the five domains. The criterion we used was the International Personality Item Pool (IPIP; (Goldberg et al., 2006) version of the NEO Personality Inventory-Revised (NEO-PI-R; (Costa and McCrae, 1992a). The IPIP NEO-PI-R was selected because (a) it was designed to measure multiple aspects of each factor of the of the FFM; (b) is in the public domain; (c) it has a statement-based 
format that matches many of the items from the Add Health surveys; (d) the NEO instruments have been used in a wide usage of clinical and research settings (Costa and McCrae, 1992a,b); and (e) the NEO-PI-R has been shown to work well in adolescent samples (De Fruyt et al., 2000). Second, we searched the Add Health Wave I In-Home and In-School questionnaires for items that lexically or conceptually matched statements from the IPIP NEO-PI-R ${ }^{1}$.

Factor analytic approach. The purpose of the factor analytic approach was twofold. The first purpose was to assess the dimensionality of the items found in the lexical approach, while the second was to examine how each of the found items measured its respective personality domain. McCrae and Costa (2004; cf. McCrae et al., 1996) recommend assessing dimensionality of NEO items via principal components analysis (PCA). Other methodologists have criticized using PCA because it was designed for use with continuous variables, but items on personality tests are typically categorical (Waller et al., 1996; Panter et al., 1997). Neglecting the continuous-variable assumption of PCA, and other traditional exploratory factor analytic (EFA) techniques, can lead to factor extraction problems because the item thresholds (difficulties) are not taken into account (Bernstein and Teng, 1989). Consequently, we assessed item dimensionality using item-level exploratory factor analysis (IL-EFA), which accounts for item thresholds by using polychoric correlations estimated via a robust weighted least squares estimator (Flora and Curran, 2004) to measure the relationship among the items (Muthén and Kaplan, 1992).

Once we determined the dimensionality of the items, we then conducted an item-response theory/confirmatory factor analysis (IRT/CFA; (Brown, 2006; Kamata and Bauer, 2008) to examine how well each of the items measured their respective personality factors/ domains. For the IRT/CFA analysis, we used a robust maximum likelihood estimator. As fit measures are not yet well developed for IRT/CFA with item-level data, and because our sample size was so large, we used the IRT/CFA estimates as a cross-validation of the EFA results (Bandalos, 1993), although we did not expect there to be large differences (Kay, 2004). Consequently, we randomly split the participants into two groups and conducted the EFA on the first group and the IRT/CFA on the second group.

To determine the number of factors to extract in the IL-EFA, we used three criteria. First, best practices in EFA (Osborne et al., 2008) suggest using more traditional techniques (e.g., minimum average partial test, MAP; (Velicer et al., 2000) to examine the number of factor to extract. Consequently, we used the MAP test with the polychoric correlations as input. To conduct the MAP test, we used the SPSS syntax provided by O'Connor (2000), which uses the original correlations (i.e., the polychoric correlations) in all the MAP test steps.

Second, we examined the IL-EFA fit statistics after extracting one to five factors. The fit statistics we used were the root mean square error of approximation (RMSEA), comparative fit index

${ }^{1}$ The survey was designed such that all participants with answers to the In-Home questionnaire also had answers to the In-School Questionnaire.
(CFI), and the standardized root mean square residual (SRMR). These indexes were chosen as they represent both absolute and relative fit indices, and they tend to perform well in simulation studies (Marsh et al., 2005). While it is tenuous to use absolute cut-off values for fit indices, usually factor models tend to do an adequate job representing the data when: (a) the RMSEA value is less than 0.08 (Chen et al., 2008); (b) the CFI value is greater than 0.96 (Yu and Muthén, 2002); and (c) the SRMR value is less than 0.08 (Sivo et al., 2006). Because fit indices tend to get better in EFA as more factors are extracted, we looked for the most parsimonious number of factors that would produce adequate values that best fit the data.

For the third criterion, we examined pattern coefficients from the various extractions to gage factor interpretability. While this is more subjective than the other methods we employed, it is still one of the most important steps in determining the number of factors to extract (Gorsuch, 1992).

Internal consistency. For each personality factor/domain we found from the previous steps, we summed the items scores within a domain and assessed the internal consistency of the scores using all the respondents in the sample. We assessed internal consistency using both Cronbach's alpha and McDonald's omega (Zinbarg et al., 2005).

Predictive validity evidence. In Wave IV (2008) of the Add Health design, the In-Home instrument purposely collected personality data based on the FFM. For each factor, the questionnaire included four questions. There were 14,800 participants who had data at both Wave I (1994-1995) and Wave IV (2008). We correlated the factor scores (using IRT/CFA) collected from the Wave I personality measure with the factor scores (again, using IRT/CFA) from the Wave IV personality measurement to examine the predictive validity of the Wave I scales.

\section{RESULTS \\ LEXICAL METHOD}

Searching the Wave I questionnaires yielded 21 items that appeared to measure neuroticism (N) (8 items), extroversion (E) (7 items), and conscientiousness (C) (6 items).

\section{FACTOR ANALYTIC METHODS}

There were missing responses for the 21 items ranging from less than 1 to $34.50 \%$ of the sample, with 24 of the respondents having no response recorded for any of the items. Consequently, the subsequent factor analyses were conducted using the 20,721 participants with at least one item score (half being used for the EFA analysis, and the other half being used for the CFA/IRT analysis). For the EFA, missing data was handled using pairwise present method (Kaplan, 2009), whereas the CFA/IRT analysis used the full information maximum likelihood estimator (Enders and Bandalos, 2001) with the delta paramaterization and logit link. All factor analyses were conducted in Mplus (Muthén and Muthén, 2010).

For the IL-EFA, the RMSEA values indicated that four factors should be extracted, but the CFI, SRMR and MAP test indicated that only three factors should be extracted. When we examined 
the pattern coefficients, we found five items across both the threeand four-factor extractions that measured little in common with the other items (i.e., all pattern coefficients $<0.30$ and all communalities $<0.14$ ). In addition, there were three additional items that had moderate pattern coefficients (between 0.48 and 0.58 ) on the four-factor solution and low coefficients $(<0.30)$ on the threefactor solution, but the content of these items did not appear to overlap with each other. Consequently, we removed these 8 items and conducted an additional IL-EFA on the remaining 13 items. The values of the IL-EFA criterion measures all converged to indicate that a three-factor solution bet fit the data. The results from both IL-EFAs are given in Table 2.

The pattern coefficients for the IL-EFA are given in the first part of Table 3. Each item had a large coefficient $(>|0.69|)$ in only one domain and small coefficients $(<|0.19|)$ for the other two domains. Thus, while the final 13 items are measuring three dimensions, each item appears to only measure one factor (i.e., the three factors the items are measuring appear to be unidimensional). The pattern coefficients from IRT/CFA are given in second part of Table 3 and, as expected, are very similar to those from the IL-EFA, with the maximum absolute difference being 0.06 .

Table 4 shows the final 13 items, similar items from the IPIP NEO-PI-R, and where they can be located in the Add Health questionnaires and database. The results from Tables 3 and 4 indicate that the 13 items used in this study are similar in content to the IPIP NEO-PI-R items that measure C, E, and N.

\section{INTERNAL CONSISTENCY}

The first two rows of data in Table 5 show the internal consistency estimates for the $\mathrm{C}, \mathrm{E}$, and $\mathrm{N}$ personality scales we developed from Wave I of the Add Health data. While the values are similar to internal consistency estimates typically found for scores on personality questionnaires (Kline, 1998), these estimates can be put into a better context by comparing them to the results of a recent meta-analysis (Caruso, 2000) of various NEO instruments' score reliability. The last two rows on data in Table 5 contain the average coefficient alpha values reported for all NEO instruments as

Table 2 | Results from the exploratory factor analysis.

\begin{tabular}{lccccc}
\hline Fit measure & \multicolumn{5}{c}{ Number of extracted factors } \\
\cline { 2 - 6 } & $\mathbf{1}$ & $\mathbf{2}$ & $\mathbf{3}$ & $\mathbf{4}$ & $\mathbf{5}$ \\
\hline \multicolumn{5}{l}{ FIRST FACTOR ANALYSIS (21 ITEMS) } \\
CFI & 0.81 & 0.92 & 0.96 & 0.98 & 0.99 \\
RMSEA & 0.15 & 0.10 & 0.08 & 0.05 & 0.04 \\
SRMR & 0.10 & 0.07 & 0.05 & 0.03 & 0.02 \\
Eigenvalue & 5.53 & 2.23 & 1.61 & 1.53 & 1.16 \\
SECOND FACTOR ANALSIS (13 ITEMS) & & \\
CFI & 0.76 & 0.90 & 0.97 & 0.99 & 1.00 \\
RMSEA & 0.20 & 0.14 & 0.08 & 0.06 & 0.04 \\
SRMR & 0.14 & 0.09 & 0.02 & 0.02 & 0.01 \\
Eigenvalue & 5.16 & 2.07 & 1.54 & 0.58 & 0.56 \\
\hline
\end{tabular}

CFI, comparative fit index; RMSEA, root mean square error of approximation; $S R M R$, standardized root mean square residual. well as the values for the shortened version of the NEO-PI-R, the NEO-Five Factor Inventory (NEO-FFI). Across the N, E, and C domains, the internal consistency estimates for the Add Health personality scales are almost identical to the averages from the NEO-FFI (largest difference: 0.04 ) and are very close to averages for all the NEO instruments (largest difference:0.07), which is remarkable given that the current scales have from 3 to 6 items, whereas the NEO-PI-R has 60 items for each scale and the NEOFFI has 12 items for each scale.

\section{PREDICTIVE VALIDITY}

The results from the analysis of the personality data gathered in Wave IV (2008) of the Add Health study is given in Table 6. As the table shows, all the Wave IV items had relatively high pattern coefficients on their intended factor. More importantly for the study of the Wave I (1994-1995) items is that the correlations between the Wave I and Wave IV factors, although modest, are in the expected directions.

\section{DISCUSSION}

The purpose of this study was to determine how to best measure personality from existing data in a longitudinal dataset that does not utilize a specific personality instrument as part of its collected data. Using survey questions from Wave I of the Longitudinal Study of Adolescent Health (Add Health), we sought to determine (a) if the survey questions from Wave I had a lexical relationship to questions from other measures specifically designed to measure personality? (b) if so, could any of the questions be aggregated

Table 3 | Factor analysis pattern coefficients.

\begin{tabular}{|c|c|c|c|c|c|c|}
\hline \multirow{3}{*}{$\begin{array}{l}\text { Add Health } \\
\text { item identifier }\end{array}$} & \multicolumn{3}{|c|}{ Personality factor } & \multicolumn{3}{|c|}{ Personality factor } \\
\hline & $N$ & $E$ & $c$ & $N$ & $E$ & $c$ \\
\hline & \multicolumn{3}{|c|}{$\begin{array}{l}\text { EFA pattern } \\
\text { coefficients }\end{array}$} & \multicolumn{3}{|c|}{$\begin{array}{l}\text { IRT/CFA pattern } \\
\text { coefficients }\end{array}$} \\
\hline H1PF18 & 0.04 & -0.01 & 0.72 & - & - & 0.76 \\
\hline H1PF19 & -0.01 & 0.01 & 0.79 & - & - & 0.82 \\
\hline H1PF20 & -0.02 & 0.03 & 0.71 & - & - & 0.73 \\
\hline H1PF21 & 0.01 & -0.02 & 0.67 & - & - & 0.69 \\
\hline H1PF30 & 0.75 & -0.01 & 0.06 & 0.78 & - & - \\
\hline H1PF32 & 0.86 & -0.02 & 0.01 & 0.87 & - & - \\
\hline H1PF33 & 0.81 & -0.01 & -0.05 & 0.79 & - & - \\
\hline H1PF34 & 0.74 & 0.01 & 0.00 & 0.74 & - & - \\
\hline H1PF35 & 0.70 & 0.17 & 0.01 & 0.78 & - & - \\
\hline H1PF36 & 0.76 & 0.08 & -0.00 & 0.81 & - & - \\
\hline S62B & -0.03 & 0.77 & 0.02 & - & 0.78 & - \\
\hline S62E & 0.01 & 0.80 & 0.02 & - & 0.82 & - \\
\hline S62O & 0.21 & 0.63 & -0.02 & - & 0.70 & - \\
\hline
\end{tabular}

$N$, neuroticism; $E$, extroversion; $C$, conscientiousness; EFA, exploratory factor analysis; IRT/CFA, item-response theory/confirmatory factor analysis. -: Coefficient constrained to be zero. The sample was randomly divided into two groups; the EFA was done in the first group and the IRT/CFA on the second. Factor correlations from the EFA: $N, E:-0.38 ; N, C: 0.44 ; E, C:-0.14$. Item stems are given in Table 4. 
Table 4 | Final personality items from Wave I of the Add Health Data.

IPIP NEO-PI-R question

Add Health item stem

Add Health

item identifier

\section{NEUROTICISM}

Have a low opinion of myself (+)

You have a lot of good qualities*

H1PF 30

Feel desperate (+)

Feel comfortable with myself (-)

You have a lot to be proud of*

H1PF 32

You like yourself just the way you are*

H1PF33

You feel like you are doing everything just about right*

Worry about things (+)

H1PF34

Fear for the worst (+)

Get caught up in my problems (+)

Am not easily bothered by things (-)

Don't worry about things that have already happened (-)

Find it difficult to approach others (+)

You feel socially accepted*

H1PF35

Am afraid to draw attention to myself (+)

Only feel comfortable with friends (+)

Stumble over my words (+)

Am comfortable in unfamiliar situations (-)

Am not bothered by difficult social situations (-)

Dislike myself ( + )

You feel wanted and loved*

H1PF36

Am often down in the dumps (+)

\section{EXTRAVERSION}

Make friends easily $(+)$

I feel close to people at school**

S62B

Warm up quickly to others (+)

I feel like I am a part of this school**

S62E

Feel comfortable around people (+)

I feel socially accepted**

$\mathrm{S} 62 \mathrm{O}$

Act comfortably with others (+)

Am hard to get to know (-)

Often feel uncomfortable around others (-)

Avoid contacts with others (-)

Am not really interested in others (-)

Keep others at a distance (-)

\section{CONSCIENTIOUSNESS}

Pay attention to details (+)

Jump into things without thinking (-)

Make rash decisions (-)

Come up with good solutions (+)

Know how to get things done $(+)$

Don't understand things (-)

Don't see the consequences of things (-)

Do things according to a plan (+)

Love order and regularity (+)

Do more than what's expected of me $(+)$

Demand quality (+)

When you have a problem to solve, one of the first things you do is get as many H1PF18 facts about the problem as possible*

When you are attempting to find a solution to a problem, you usually try to think H1PF19 of as many different ways to approach the problem as possible*

When making decisions, you generally use a systematic method for judging and H1PF20 comparing alternatives*

After carrying out a solution to a problem, you usually try to analyze what went H1PF21 right and what went wrong*

Am not highly motivated to succeed (-)

Do just enough work to get by (-)

Put little time and effort into my work (-)

IPIP NEO-PI-R, International Personality Item Pool version of the NEO Personality Inventory-Revised. +: positively keyed item, -: negatively keyed item, *: indicates items from In-Home questionnaire, **: indicates items from In-School questionnaire. 
to form a scale? (c) if questions could be aggregated, what is the internal consistency of such scales? and (d) do these scales actually measure personality factors?

We compared the questions used in Wave I of the Add Health study with items from the IPIP (Goldberg et al., 2006) version of the NEO-PI-R (Costa and McCrae, 1992a). Then we subjected those items to an item-level factor analyses to determine what items to keep, as well as the dimensionality of the domains the items measured. We found that there were 13 items that measured neuroticism $(\mathrm{N})$, extroversion (E), and conscientiousness (C) - three of the major super-ordinate dimensions of personality. Although there were only a few items in each of these three personality domains, the factor structure of the items indicates they each measure only one construct (i.e., domain scores are unidimensional) and the N, E, and C scores appear to have internal consistency estimates (alpha coefficients ranging from 0.76 to 0.86 ) similar to NEO Personality instruments, which measure the $\mathrm{N}, \mathrm{E}$, and $\mathrm{C}$ constructs with 3- to 10-times as many items. Furthermore, the factors from Wave I had a modest correlation in the expected direction with the factors from Wave IV. There are

Table 5 | Reliability estimates for Add Heath Wave I personality scores.

\begin{tabular}{|c|c|c|c|}
\hline Internal consistency estimate & $N$ & $E$ & $c$ \\
\hline Alpha & 0.86 & 0.76 & 0.76 \\
\hline Omega & 0.91 & 0.81 & 0.83 \\
\hline $\begin{array}{l}\text { Average alpha coefficient } \\
\text { for all NEO instruments }{ }^{1}\end{array}$ & 0.88 & 0.83 & 0.83 \\
\hline $\begin{array}{l}\text { Average alpha coefficient } \\
\text { for the NEO-Five Factor Inventory }{ }^{2}\end{array}$ & 0.83 & 0.75 & 0.80 \\
\hline
\end{tabular}

$N$, neuroticism; E, extroversion; C, conscientiousness. Omega estimates were derived from the confirmatory factor analysis/item-response theory pattern coefficients.

${ }^{1}$ Caruso (2000, p. 242).

${ }^{2}$ Caruso (2000, p. 246). a few possible reasons for the weak correlations between the two waves of data collection, such as the amount of time between data collection of Wave I and Wave IV, personality being measured in early adolescence, or the possibility of poor measurement of the construct in Wave IV.

\section{CONCLUSION}

The Add Health study uses longitudinal survey data, combined with contextual data, to study how the relationship of social environments and behaviors in adolescence influence health and achievement outcomes. The data is accessible in both public and restricted use formats. The public-use data is free for downloading from two sources, but is limited in the variables that can be accessed. Specific instructions for accessing the Add Health data, as well as the variables included in the public and restricted use files, are found at http://www.cpc.unc.edu/projects/addhealth/ data. Having measures of personality in the Add Health data provide opportunity for the investigation of child/adolescent personality to a myriad of physical and mental health outcomes, both proximally (in childhood/adolescence) and distally (in adulthood). Specifically, neuroticism, extroversion, and conscientiousness could be included in models investigating physical and psychological health outcomes such as depression, substance abuse, and pregnancy in adolescence and early adulthood; data that is included in the Add Health study.

Furthermore, existing personality research suggests that various personality traits tend to moderate or mediate the relationship of several mental health outcomes, such as depression (Ayotte et al., 2009) and eating disorders (Eggert et al., 2007) and the interactive relationship of specific traits, such as extroversion and neuroticism, are related to overall well being (Lynn and Steel, 2006). Having measures of personality in a large, longitudinal dataset, such as the Add Health dataset, allows researchers to investigate the nature of the relationship (mediating, moderating, or interactive) of personality traits to other variables associated with various mental and physical health outcomes.

\section{Table 6 | Wave IV results.}

\begin{tabular}{|c|c|c|c|c|}
\hline Item identifier & Item stem & Neuroticism & Extraversion + & Conscientiousness ++ \\
\hline H4PE12 & I am relaxed most of the time & 0.523 & - & - \\
\hline H4PE28 & I seldom feel blue & 0.402 & - & - \\
\hline H4PE1* & I am the life of the party & - & 0.642 & - \\
\hline H4PE9 & I don't talk a lot & - & 0.641 & - \\
\hline H4PE25 & I keep in the background & - & 0.788 & - \\
\hline H4PE3 & I get chores done right away & - & - & 0.626 \\
\hline H4PE11 & I often forget to put things back in their proper place & - & - & 0.672 \\
\hline H4PE19* & I like order & - & - & 0.531 \\
\hline H4PE27 & I make a mess of things & - & - & 0.689 \\
\hline
\end{tabular}

Wave IV data $n=14,800$; weights, strata, and cluster variables were used. *: Reversed coded items, +: Scaled so that higher scores are introversion, ++: Scaled to be un-conscientiousness. 
This study also provides a method for creating measures of personality from other large-scale studies, potentially allowing researchers to investigate personality-related outcomes within the context of other large datasets. The ability to create personality measures within other large-scale data sets allows researchers to further investigate the relationship of personality traits to other mental and physical health outcomes not included in the Add Health study, but nonetheless important in serving mental and physical health needs of children and adolescents that have potential ramifications throughout the lifespan.

Despite the size of the sample and strength of methods employed, the current study is not without limitations. One limitation is the inability to directly compare how the scores from the personality factors extracted in this study relate to scores of other standardized measures of personality. Another limitation is that because the Add Health study did not use a specific measure of personality, we could only extract three of the five major personality factors, and the factors we could extract are made up of only limited number of items.

\section{REFERENCES}

Ayotte, B. J., Potter, G. G., Williams, H. T., Steffens, D. C., and Bosworth, H. B. (2009). The moderating role of personality factors in the relationship between depression and neuropsychological functioning among older adults. Int. J. Geriatr. Psychiatry 24, 1010-1019.

Bandalos, D. L. (1993). Factors influencing cross-validation of confirmatory factor analysis models. Multivariate Behav. Res. 28, 351-374.

Barenbaum, N. B., and Winter, D. G. (2008). "History of modern personality theory and research," in Handbook of Personality: Theory and Research, eds O. P. John, R. W. Robins, and L. A. Pervin (New York: Guliford Press), 3-26.

Beier, M. E., and Ackerman, P. L. (2003). Determinants of health knowledge: an investigation of age, gender, abilities, personality, and interests. J. Pers. Soc. Psychol. 84, 439-447.

Bernstein, I. H., and Teng, G. (1989). Factoring items and factoring scales are different: evidence for multidimensionality due to item categorization. Psychol. Bull. 105, 465-477.

Booth-Kewley, S., and Vickers, R. R. Jr. (1994). Associations between major domains of personality and health behavior. J. Pers. 62, 281-298.

Brown, T. A. (2006). Confirmatory Factor Analysis for Applied Research. New York: Guilford Press.

Caruso, J. C. (2000). Reliability generalization of the NEO personality scales. Educ. Psychol. Meas. 60, 236-254.

Caspi, A., and Roberts, B. W. (2001). Personality development across the life course: the argument for change and continuity. Psychol. Inq. 12, 49-66.

Caspi, A., Roberts, B. W., and Shiner, R. L. (2005). Personality development: stability and change. Annu. Rev. Psychol. 56, 453-484.

Chen, F., Curran, P. J., Bollen, K. A., Kirby, J., and Paxton, P. (2008). An empirical evaluation of the use of fixed cutoff points in RMSEA test statistic in structural equation models. Sociol. Methods Res. 36, 462-494.

Clarke, S., and Robertson, I. T. (2005). A meta-analytic review of the Big Five personality factors and accident involvement in occupational and nonoccupational settings. J. Occup. Organ. Psychol. 78, 355-376.

Costa, P. T. Jr., and McCrae, R. R. (1992a). NEO Personality Inventory (NEO$P I-R)$ and NEO Five-Factor Inventory (NEO-FFI) Professional Manual. Odessa, FL: Psychological Assessment Resources Inc.

Costa, P. T. Jr., and McCrae, R. R. (1992b). Normal personality assessment in clinical practice: the NEO Personality Inventory. Psychol. Assess. 4, 5-13.

Costa, P. T. Jr., and McCrae, R. R. (1994). "Stability and change in personality from adolescence through adulthood," in The Developing Structure of Temperament and Personality from Infancy to Adulthood, eds C. F. J. Halverson, G. A. Kohnstamm, and R. P. Martin (Hillsdale, NJ: Lawrence Erlbaum), 139-150.

De Fruyt, F., Mervielde, I., Hoekstra, H. A., and Rolland, J. P. (2000). Assessing adolescents' personality with the NEO PI-R. Assessment 7, 329-345.

Deary, I. J., Weiss, A., and Batty, G. D. (2010). Intelligence and personality as

\section{AUTHOR'S NOTES}

A. Alexander Beaujean was supported by Award Number R03HD058464 from the Eunice Kennedy Shriver National Institute of Child Health and Human Development. The content is solely the responsibility of the authors and does not necessarily represent the official views of the Eunice Kennedy Shriver National Institute of Child Health and Human Development or the National Institutes of Health.

This research uses data from Add Health, a program project designed by J. Richard Udry, Peter S. Bearman, and Kathleen Mullan Harris, and funded by a grant P01-HD31921 from the Eunice Kennedy Shriver National Institute of Child Health and Human Development, with cooperative funding from 17 other agencies. Special acknowledgment is due Ronald R. Rindfuss and Barbara Entwisle for assistance in the original design. Persons interested in obtaining data files from Add Health should contact Add Health, Carolina Population Center, 123 W. Franklin Street, Chapel Hill, NC 27516-2524 (addhealth@unc.edu).No direct support was received from grant P01-HD31921 for this analysis.

predictors of illness and death. Psychol. Sci. Public Int. 11, 53-79.

Digman, J. M. (1990). Personality structure: emergence of the fivefactor model. Annu. Rev. Psychol. 41, 417-440.

Duncan, G. J., Boisjoly, J., and Harris, K. M. (2001). Sibling, peer, neighbor, and schoolmate correlations as indicators of the importance of context for adolescent development. Demography 38, 437-447.

Eggert, J., Levendosky, A., and Klump, K. (2007). Relationships among attachment styles, personality characteristics, and disordered eating. Int. J. Eat. Disord. 40, 149-155.

Enders, C. K., and Bandalos, D. L. (2001) The relative performance of full information maximum likelihood estimation for missing data in structural equation models. Struct. Equ. Modeling 8, 430-457.

Eysenck, H. J., and Eysenck, M. W. (1985). Personality and Individual Differerences: A Natural Science Approach. New York: Plenum Press.

Filer, R. K. (1986). The role of personality and tastes in determining occupational structure. Ind. Labor Relat. Rev. 412-424.

Flora, D. B., and Curran, P. J. (2004). An empirical evaluation of alternative methods of estimation for confirmatory factor analysis with ordinal data. Psychol. Methods 9, 466-491.

Floyd, F. J., and Widaman, K. F. (1995). Factor analysis in the development and refinement of clinical assessment instruments. Psychol. Assess. 7, 286-299.

Goldberg, L. R., Johnson, J.A., Eber, H.W., Hogan, R., Ashton, M. C., Cloninger,
C. R., and Gough, H. G. (2006). The international personality item pool and the future of public-domain personality measures. J. Res. Pers. 40, 84-96.

Goodwin, R. G., and Friedman, H. S. (2006). Health status and the Five Factor personality traits in a nationally representative sample. J. Health Psychol. 11, 643-654.

Gorsuch, R. L. (1992). Factor Analysis, 2nd Edn. Hillsdale, NJ: Lawrence Erlbaum.

Hampson, S. E., Goldberg, L. R., Vogt, T. M., and Dubanoski, J. P. (2006). Forty years on: teacher's assessments of children's personality traits predict self-reported health behaviors and outcomes at midlife. Health Psychol. 25, 57-64.

John, O. P., Angleitner, A., and Ostendorf, F. (1988). The lexical approach to personality: a historical review of trait taxonomic research. Eur. J. Pers. 2, 171-203.

Judge, T. A., Higgins, C. A., Thoresen, C. J., and Barrick, M. R. (1999). The big five personaltiy traits, general mental ability, and career success across the life span. Pers. Psychol. 52, 621-652.

Kamata,A., and Bauer, D. J. (2008). A note on the relation between factor analytic and item response theory models. Struct. Equ. Modeling 15, 136-153.

Kaplan, D. (2009). Structural Equation Modeling: Foundations and Extensions, 2nd Edn. Thousand Oaks, CA: Sage.

Kay, C. A. (2004). A Comparison of Traditional and IRT Factor Analysis. Dissertation/thesis, University of North Texas, Denton, TX.

Kern, M. L., and Friedman, H. S. (2008). Do conscientious individuals live 
longer? A quantitative review. Health Pyschol. 27, 505-512.

Kline, P. (1998). The New Psychometrics: Science, Psychology, and Measurement. London: Routledge.

Loehlin,J.C.(1992). Genesand Environment in Personality Development. Thousands Oaks, CA: Sage.

Lohman, D. F., and Rocklin, T. (1995). "Current and recurring issues in the assessment of intelligence and personality," in International Handbook of Personality and Intelligence, eds D. H. Saklofske and M. Zeidner (New York: Plenum Press), 447-474.

Lynn, M., and Steel, P. (2006). National differences in subjective well-being: the interactive effects of extraversion and neuroticism. J. Happiness Stud. 7, 155-165.

Marsh, H.W., Hau, K.-T., and Grayson, D. (2005). "Goodness of fit in structural equation models," in Contemporary Psychometrics: A Festschrift for Roderick P. McDonald, eds A. MaydeuOlivares and J. J. McArdle (Mahwah, NJ: Lawrence Erlbaum), 275-340.

Marshall, G. N., Wortman, C. B., Vickers, R. R., Kusulas, J. W., and Hervig, L. K. (1994). The five-factor model of personality as a framework for personality-health research. J. Pers. Soc. Psychol. 67, 278-286.

Martin, L. R., Friedman, H. S., and Schwartz,J.E. (2007). Personality and mortality risk across the life span: the importance of conscientiousness as a biopsychosocial attribute. Health Pyschol. 26, 428-436.

McCrae, R. R., and Allik, J. (2002). The Five-Factor Model of Personality Across Cultures. New York: Kluwer.

McCrae, R. R., and Costa, P. T. Jr. (1997). Personality trait structure as a human universal. Am. Psychol. 52, 509-516.

McCrae, R. R., and Costa, P. T. Jr. (2003). Personality in Adulthood:A Five-Factor Theory Perspective, 2nd Edn. New York: Guilford Press.

McCrae, R. R., and Costa, P. T. Jr. (2004). A contemplated revision of the NEO
Five-Factor Inventory. Pers. Indiv. Differ. 36, 587-596.

McCrae, R. R., and Costa, P. T. Jr. (2008). "A five-factor theory of personality," in Handbook of Personality: Theory and Research, Vol. 3, eds L. A. Pervin, O. P. John, and R. W. Robins (New York: Guilford Press), 159-181.

McCrae, R. R., Zonderman, A. B., Costa, P. T. Jr., Bond, M. H., and Paunonen, S.V. (1996). Evaluating replicebility of factors in the Revised NEO Personality inventory: confirmatory factor analysis versus procrustes rotation. J. Pers. Soc. Psychol. 70, 552-566.

Muthén, B. O., and Kaplan, D. (1992). A comparison of some methodologies for the factor analysis of non-normal Likert variables. Br. J. Math. Stat. Psychol. 38, 171-189.

Muthén, L. K., and Muthén, B. O. (2010). Mplus (Version 6) [Computer Software]. Los Angeles, CA: Muthén and Muthén.

O'Connor, B.P. (2000). SPSS and SAS programs for determining the number of components using parallel analysis and Velicer's MAP test. Behav. Res. Methods Instrum. Comput. 32, 396-402.

Ones, D. S., Viswesvaran, C., and Schmidt, F. L. (1993). Comprehensive metaanalysis of integrity test validities: findings and implications for personnel selection and theories of job performance. J. Appl. Psychol. 78, 679-703.

Osborne, J.W., Costello, A. B., and Kellow, J. T. (2008). "Best practices in exploratory factor analysis," in Best Practices in Quantitative Methods, ed. J. W. Osborne (Los Angeles, CA: Sage), 86-99.

Panter, A. T., Swygert, K. A., Dahlstrom, W. G., and Tanaka, J. S. (1997). Factor analytic approaches to personality item-level data. J. Pers. Assess. 68, 561-589.

Poropat, A. E. (2009). A meta-analysis of the five-factor model of personality and academic performance. Psychol. Bull. 135, 322-338.
Roberts, B. W., Kuncel, N. R., Shiner, R. Caspi, A., and Goldberg, L. R. (2007). The power of personality: the comparative validity of personality traits, socioeconomic status, and cognitive ability for predicting important life outcomes. Perspect. Psychol. Sci. 2, 313-345.

Schwartz, J. E., Friedman, H. S., Tucker, J. S., Tomlinson-Keasey, C., Wingard, D. L., and Criqui, M. H. (1995). Sociodemographic and psychosocial factors in childhood as predictors of adult mortality. Am. J. Public Health 85, 1237-1245.

Sivo, S. A., Fan, X., Witta, E. L., and Willse, J. T. (2006). The search for "optimal" cutoff properties: fit index criteria in structural equation modeling. J. Exp. Educ. 74, 267-288.

Smith, T.W. (2006). Personality as risk and resilience in physical health. Curr. Dir. Psychol. Sci. 15, 227-231.

Stankov, L., Boyle, G. J., and Cattell, R. B. (1995). "Models and paradigms in personality and intelligence research," International Handbook of Personality and Intelligence, eds D. H. Saklofske and M. Zeidner (New York: Plenum Press), 15-44.

Sümer, N., Lajunen, T., and Ozkan, T. (2005). "Big five personality traits as the distal predictors of road accident involvement," in Traffic and Transport Psychology: Theory and Application: Proceedings of the International Conference on Traffic and Transport Psychology 2004, ed. G. Underwood (Nottingham: Elsevier), 215-227.

Udry, J. R., and Bearman, P. S. (1998). "New methods for new research on adolescent sexual behavior," in New Perspectives on Adolescent Risk Behavior, ed. R. Jessor (Cambridge: Cambridge University Press), 241-269.

Velicer, W. F., Eaton, C. A., and Fava, J. L. (2000). "Construct explication through factor or component analysis: a review and evaluation of alternative procedures for determining the number of factors or components," in Problems and Solutions in Human
Assessment: Honoring Douglas N. Jackson at Seventy, eds R. D. Goffin and E. Helmes (Norwell: Kluwer Academic Publishers), 41-71.

Waller, N. G., Tellegen, A., McDonald, R. P., and Lykken, D. T. (1996). Exploring nonlinear models in personality assessment: development and preliminary validation of a negative emotionality scale. J. Pers. 64, 545-576.

Yu, C. Y., and Muthén, B. O. (2002). Evaluation of Model Fit Indices for Latent Variable Models with Categorical and Continuous Outcomes. Unpublished Doctoral Dissertation, University of California, Los Angeles.

Zinbarg, R. E., Revelle, W., Yovel, I., and Li, W. (2005). Cronbach's alpha, Revelle's beta, and McDonald's omega: their relations with each other and two alternative conceptualizations of reliability. Psychometrika 70, 123-133.

Conflict of Interest Statement: The authors declare that the research was conducted in the absence of any commercial or financial relationships that could be construed as a potential conflict of interest.

Received: 08 February 2011; paper pending published: 26 March 2011; accepted: 23 June 2011; published online: 13 July 2011. Citation: Young JK and Beaujean AA (2011) Measuring personality in wave I of the national longitudinal study of adolescent health. Front. Psychology 2:158. doi: 10.3389/fpsyg.2011.00158

This article was submitted to Frontiers in Quantitative Psychology and Measurement, a specialty of Frontiers in Psychology.

Copyright $\odot 2011$ Young and Beaujean. This is an open-access article subject to a non-exclusive license between the authors and Frontiers Media SA, which permits use, distribution and reproduction in other forums, provided the original authors and source are credited and other Frontiers conditions are complied with. 